\title{
A Case Study - Resistance Spot Welding Distortions ACCORDING To SeVeral Welding SEQuenceS
}

\author{
Yurci, C.; AKdogan, A. \& DURAKBASA, N.
}

\begin{abstract}
Resistance spot welding is one of the most commonly used manufacturing methods when steel sheets are joined. It is important to see the whole process with its defects after manufacturing, before the process. The finite element solution plays a big factor in this step. In this study these defects have been accepted as the distortions after spot welding. Although they are not as big as in the beam welding processes distortions play a role in the spot welding of steels especially if they are considered as cumulative. One of the factors affecting on such distortions is the welding sequence. In this study, distortions will be obtained according to the scanning and analysing methods (Local Shrinkage Analysis) after applying several sequences and they will be compared. This research will be made on a case study which deals with an assembly group obtained from automotive sector.
\end{abstract}

Key words: Resistance Spot Welding, Welding Sequence, Local Shrinkage Analysis, Scanning, Analysing
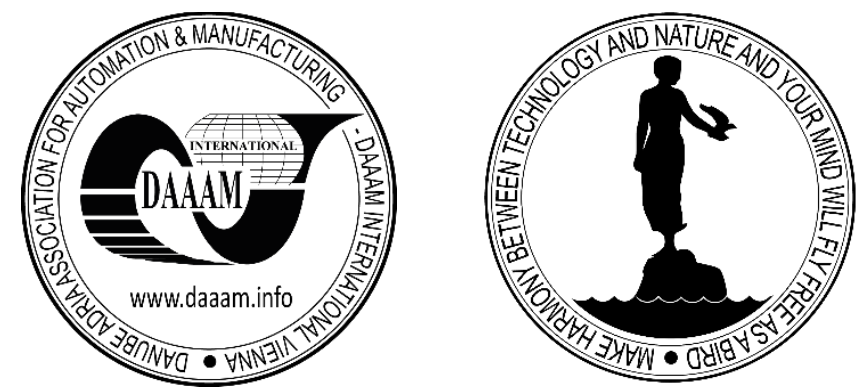

Authors' data: PhD. Student Y[urci], Cem*; Assoc. Prof. Dr. A[kdogan], Anil*; Univ.Prof. Prof.h.c. Dipl.-Ing. Dr.techn. Dr.h.c. D[urakbasa], M. Numan**, * Yildiz Technical University, Mechanical Engineering Department, Barbaros Bulvari, 34349, Yildiz, Istanbul, Turkey, ** Vienna University of Technology, Institute of Production Engineering and Laser Technology, Karlsplatz 13, 1040, Vienna, Austria, yurci_cem@yahoo.com, nomak@yildiz.edu.tr, durakbasa@mail.ift.tuwien.ac.at

This Publication has to be referred as: Yurci, C[em]; Akdogan, A[nil] \& Durakbasa, N[uman] (2017). A Case Study - Resistance Spot Welding Distortions According to Several Welding Sequences, Chapter 13 in DAAAM International Scientific Book 2017, pp.155-172, B. Katalinic (Ed.), Published by DAAAM International, ISBN 9783-902734-12-9, ISSN 1726-9687, Vienna, Austria

DOI: $10.2507 /$ daaam.scibook.2017.13 
Yurci, C.; Akdogan, A. \& Durakbasa, N.: A Case Study - Resistance Spot Weldin...

\section{Introduction}

The sheet metal industry is a very important sector for the economics of the whole world especially because of the automotive sector. However resistance welding is used in many other important sectors, too such as in motors, electrotechnology, engine building, chemistry, building industry, household appliances, food processing industry, measuring and control technology and medical technology according to (Schreiber et al., 2016). In the automotive sector by producing an automobile resistance spot welding plays a very important role by generating the body of the automobile.

Because the body of an automobile consists of many parts and they are joined mostly with spot welding. An automobile consists of approximately 30000 parts and almost 4500-4800 spot points are assigned to an automobile. Today pasting and the combination of two methods (welding and pasting) are employed, too as shown in the study of (Bielenin et al., 2016). Also resistance spot welding is not only directly applied in an automobile fabric but also for example in its Tier 1 suppliers. They have to provide convenient conditions for the produced parts, too according to the quality specifications of their co-worked automobile fabrics. The spot welding can be implemented manually or with robots. It is obvious that by the manual method controlling of factors is harder. There can be seen misalignment between the upper and lower electrode and it can be that some mistakes are made during the application of the welding sequence, which is the main topic of this study. The planning of welding sequence, which has to be prepared at the beginning, is very important for the joining of group elements.

(Zhang \& Senkara, 2012) count the most effective factors in resistance welding as welding current, welding time and electrode force. Besides, welding sequence is important in all of welding types, also in resistance spot welding, too. This property has another importance in spot welding due to the shunt effect (Fig.1) according to (Bi et al., 2016) and (Zhang \& Senkara, 2012).

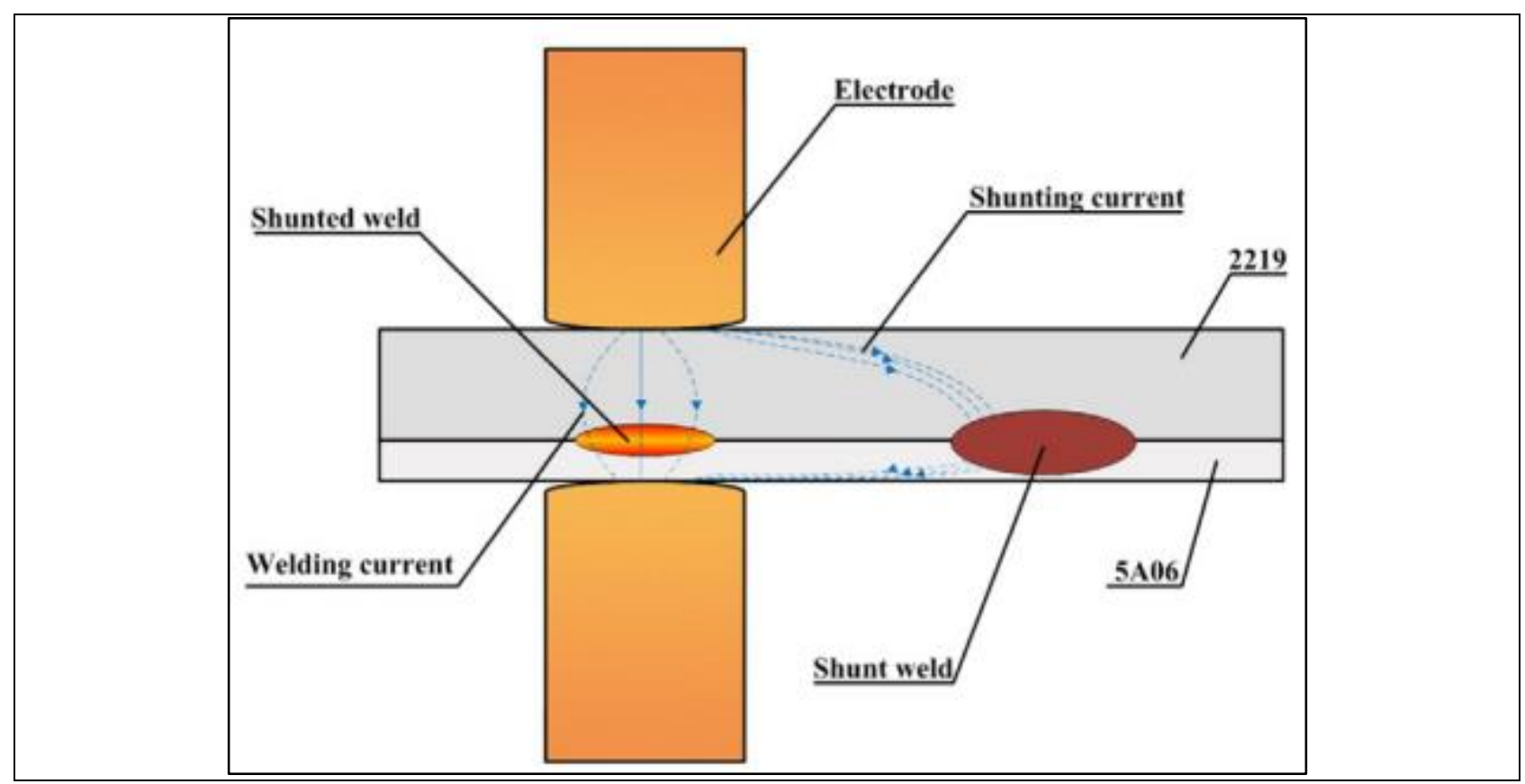

Fig. 1. Illustration of Shunt Effect 
By shunt effect a part of the current flows into the direction of another spot point. So, the current and energy input into the welded area is reduced. It can be that in this manner the distortions on the sheet are decreased, too for example on the constrained sequence in Fig. 2 [3] from the book of (Zhang \& Senkara, 2012). But in our other studies it has been proved that not every time if the current is increased the distortions are increased. It is dimension and form dependent.

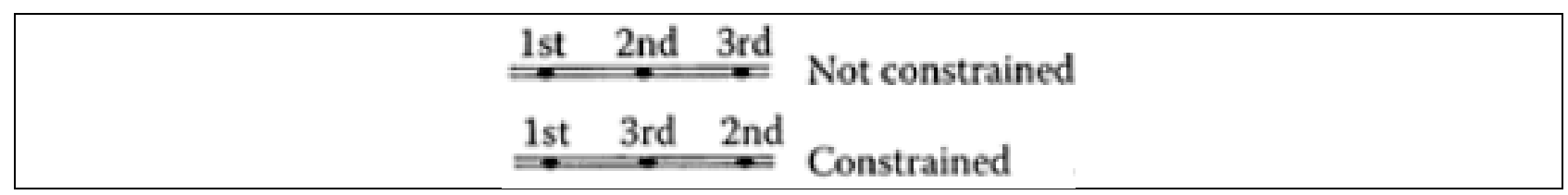

Fig. 2. Two welding sequences for explaining the welding sequence

The process parameters affecting on welding distortions were studied in many other studies. But in the literature there are a very few studies concerning the weld sequence in resistance spot welding. Also, it is being seen with the shunt effect, too that the distance between spot points have an importance. The allowed distance between spots is given in DIN EN ISO 14373.

The welding sequence by spot welding does not take a place in the literature. But there are many studies about beam welding when distortions are researched. Some examples can be given at that point. (Doyen et al., 2017) investigated the welding sequence by multipass weld for Gas Tungsten Arc Welding of a multi-chamber box structure including many channels. According to this study, one of the solutions to minimize welding distortions is to make the weld pass order from one groove side to another. This can be used in spot welding by having made necessary changes, too. In addition, (Fu et al., 2016) found out the conclusion and proved again for the welding of T-Joints that the welding sequences have important effects on the residual stresses and distortions. He worked both with FE-Method and experiments. These effects are valid for magnitude and distribution mode. He concluded that the distortion in doubleside welds is smaller than that in the single-side welds both in progressive welds. The single-side weld sequence causes more distortion than double-side weld sequence in the T-joint weld. Besides residual stress and distortions have to be thought together. (Chen et al., 2015) dealt in their study with a stiffened plate structure with longitudinal and transverse stiffeners for the manufacturing of marine structures. They have used for it thermal-plastic FE method and simulated six welding sequences. They reached to the importance of the welding sequence when affecting on residual distortion and stress, too. Welding sequences especially affect on the magnitude of panel bending distortion. He proposed, too that the distortions after bending can be improved by applying the proper welding sequence. Such improvements can be implemented by spot welding, too. (Catana, 2010) investigated not the welding sequence but the pattern arrangement (similar to welding sequence) to find the most convenient pattern under traction stress. He used both simulation and test results. He found the square arrangement the best solution as the most convenient solution. Also, this study shows the importance of spot welding location as to the strength. 
(Sulaiman et al., 2011) tried to predict welding distortions in their study for Gas Metal Arc Welding. They used for it the FEM software Weld Planner and conducted experiments too for the comparison in butt and T-Joints. They found out that distortion results can match in an acceptable accuracy. Also the shrinkage analysis method is a big nominee for estimating the welding distortions. (Folchi, 2014) gave in his masterthesis study a place to Weld Planner applications and he achieved some results. During that, he compared the software with the software Sysweld (again of ESI Group) which makes transient analysis. The main goal of Weld Planner is reducing the calculation time. But it has the disadvantage by giving clamping conditions. The clamping times can not be given and the results can not be estimated when clampings are released at high temperatures. But finally (Folchi, 2014) proposed that the shrinkage method estimates welding distortions better than the transient analysis because the input of parameters is less and simple. Besides, (Jackson \& Darlington, 2011) share the idea with Folchi and proved that with an aero-engine assembly that the rapid solution property of shrinkage technique provides many advantages during the product development process. Besides, the results were again very similar to the Sysweld results.

Sheet metal assembly by means of resistance welding is another important issue and it is directly connected with variational analysis. In this context, for example (Shaoyun et al., 2006) present in their study geometrical models for both slip and butt joints. Besides, (Dahlström et al., 2007) added placing of parts in a fixture, clamping and joining of parts together to sheet metal assembly variation analysis. (Moos \& Vezetti, 2015) introduced welding sequence to the variational assemblies together with the effects of fixturing and resistance spot welding process (for example welding cap closure).

(Mrvar et al., 2011) tried three different welding sequences and clamping conditions for a pipe in a hydropower plant with Sysweld for distortion prediction (which belongs to ESI Group, too). There are many examples with Sysweld when compared with Weld Planner such as in the studies of (Neumann et al., 2010), (Shanmugam et al., 2010) and (Francis, 2012)' master thesis.

In this work as a case study the right chassis arm of an automobile's body will be investigated. This industrial example has been obtained from TOFAS. This montage group belongs to the model FIAT USA Doblo and consists of 4 singular parts. The firm TOFAS in Turkey is the Turkish automotive company with the shareholding of Fiat Chrysler Automobiles (FCA). Although this montage group belongs to the automotive sector, this group can be accepted as a general example because the dimensions and forms of the parts can change by several sectors but the main principle by the method is the same. The materials of the parts are HSLA steels. Three of them are galvanized $\mathrm{FEE} 340 \mathrm{ZNT} / \mathrm{F} / 2 \mathrm{~S}$ steels and the other one is the bake hardening galvanized FEE 220 $\mathrm{BH}-\mathrm{ZNT} / \mathrm{F} / 2 \mathrm{~S}$ steel. 
Two welding sequences have been determined after observing the welding sequence and the assembly process on-line. The determined sequences are as below (Fig. 3). In the first sequence the first spot welding points have been assigned through the long part. The spot points in the second sequence have been applied beginning with the points along the upper curved part.
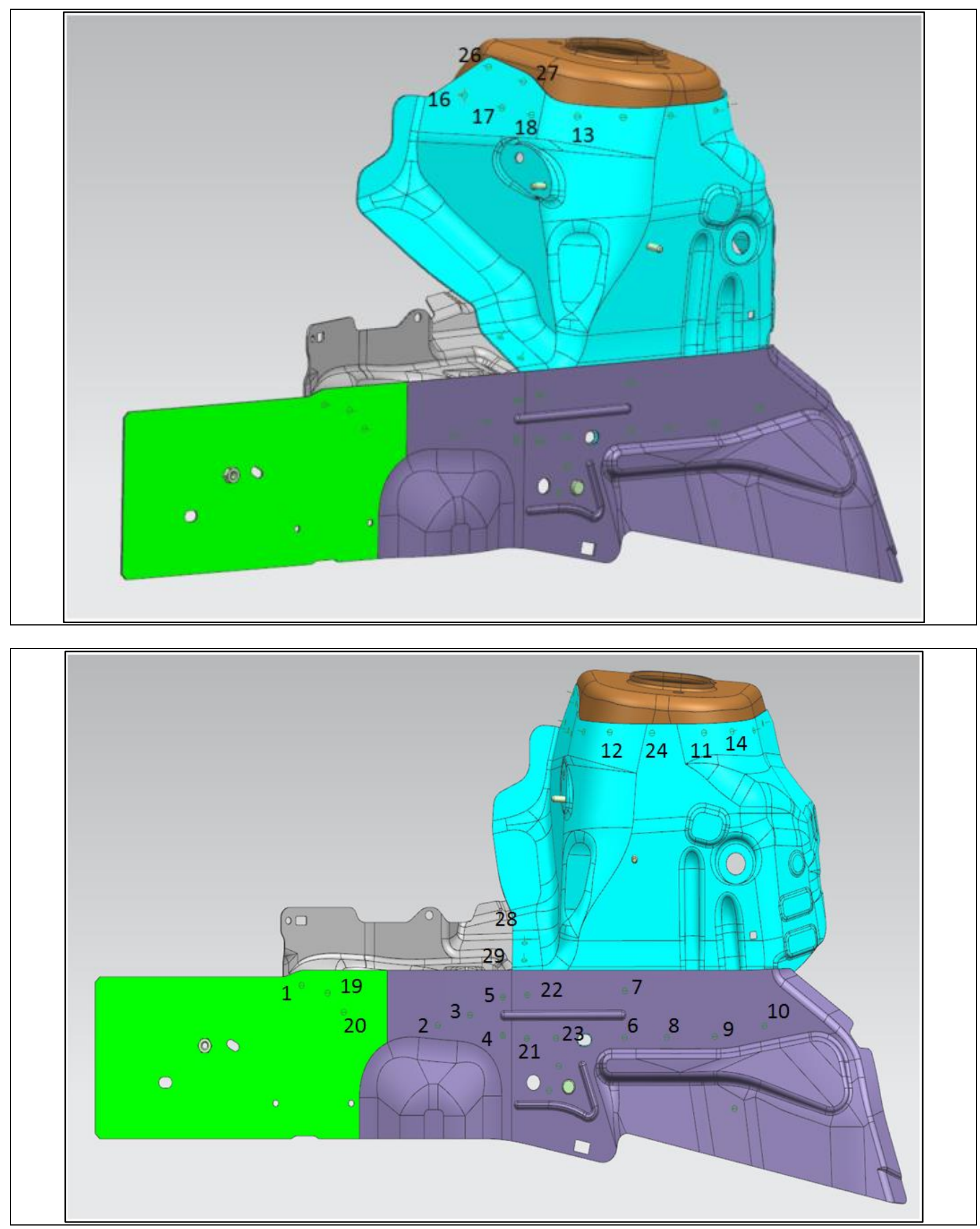
Yurci, C.; Akdogan, A. \& Durakbasa, N.: A Case Study - Resistance Spot Weldin...

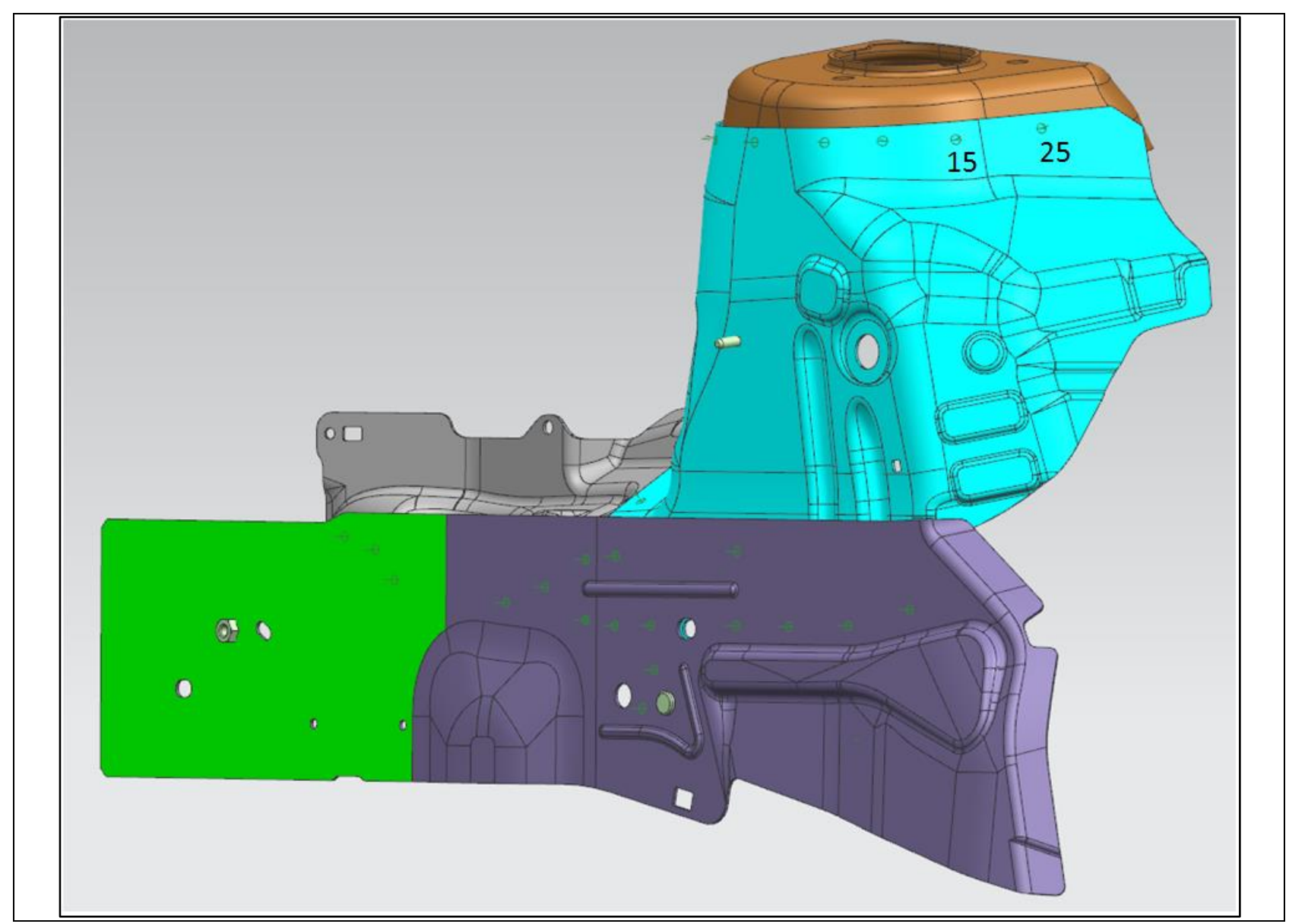

\section{Sequence 1}

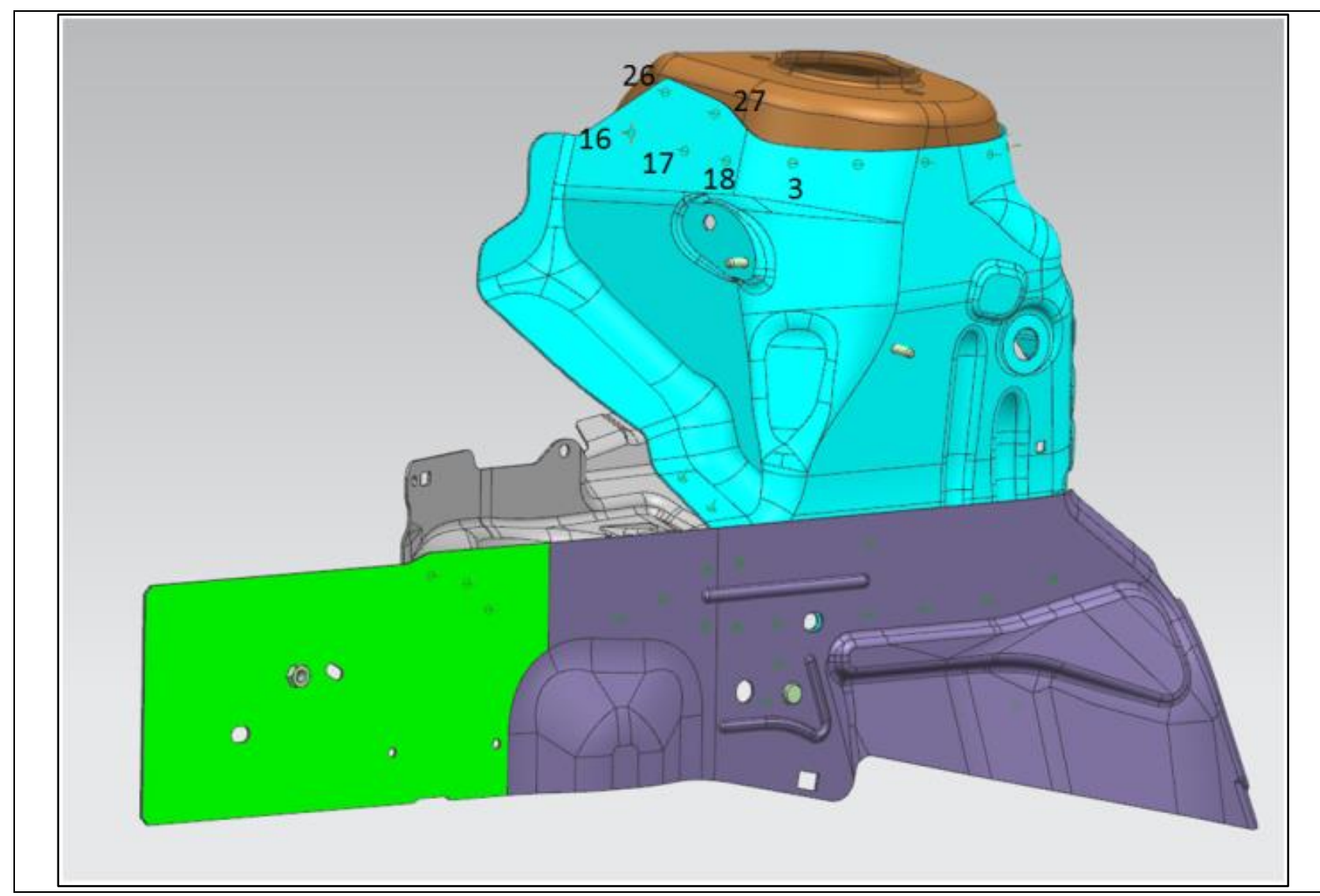



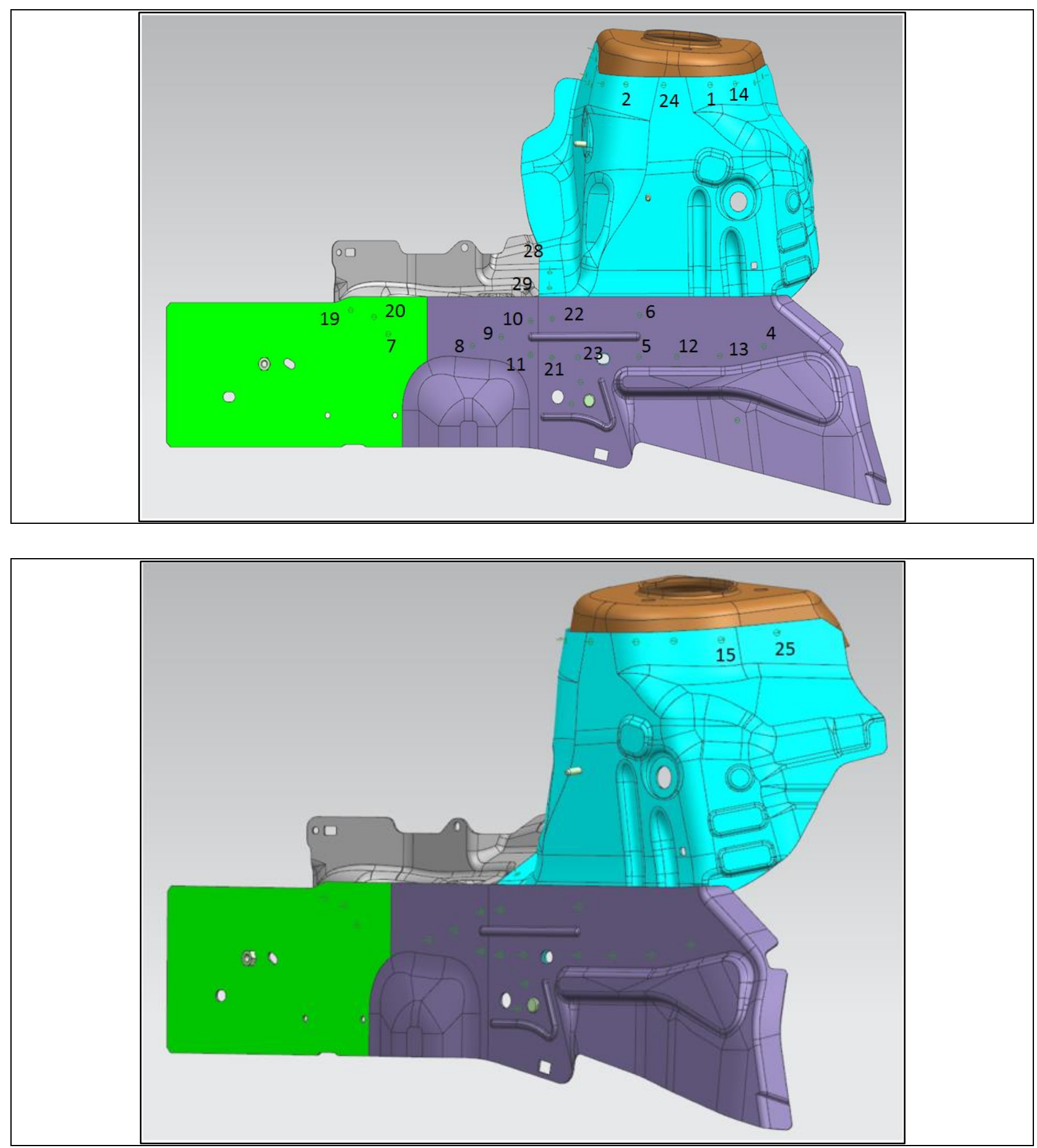

\section{Sequence 2}

Fig. 3. Applied welding sequences for the assembly group

The surfaces to be welded of the singular parts of these montage groups have been scanned and numbered. Then according to these numbers these parts have been welded and the assembly groups after welding have been scanned. From these scans the deviations before the welding process and after the welding process have been obtained. The distortions before welding are the deviations after forming of singular parts; for example springbacks. From the difference between these two deviation datas the spot welding distortions can be extracted. 
Yurci, C.; Akdogan, A. \& Durakbasa, N.: A Case Study - Resistance Spot Weldin...

\section{Experimental Procedure}

\subsection{Scanning of the singular and assembled parts}

The singular parts to be welded are shown in Fig. 4. Scanning has been made with the model Romer, Steinbichler and Nikon Scan Arm devices. (Fig. 5). The clamping plays here a very important role (Fig. 5). The analyses will be made according to these clamping points during the welding procedure. The fixed points during welding and measuring will coincide. Clamping has been made according to the directions and regions which are given in the technical drawings of the parts (Fig. 6). Besides, the aligning process (during RPS) for the data of the singular and assembled parts will be made in the software Polyworks according to these reference points.

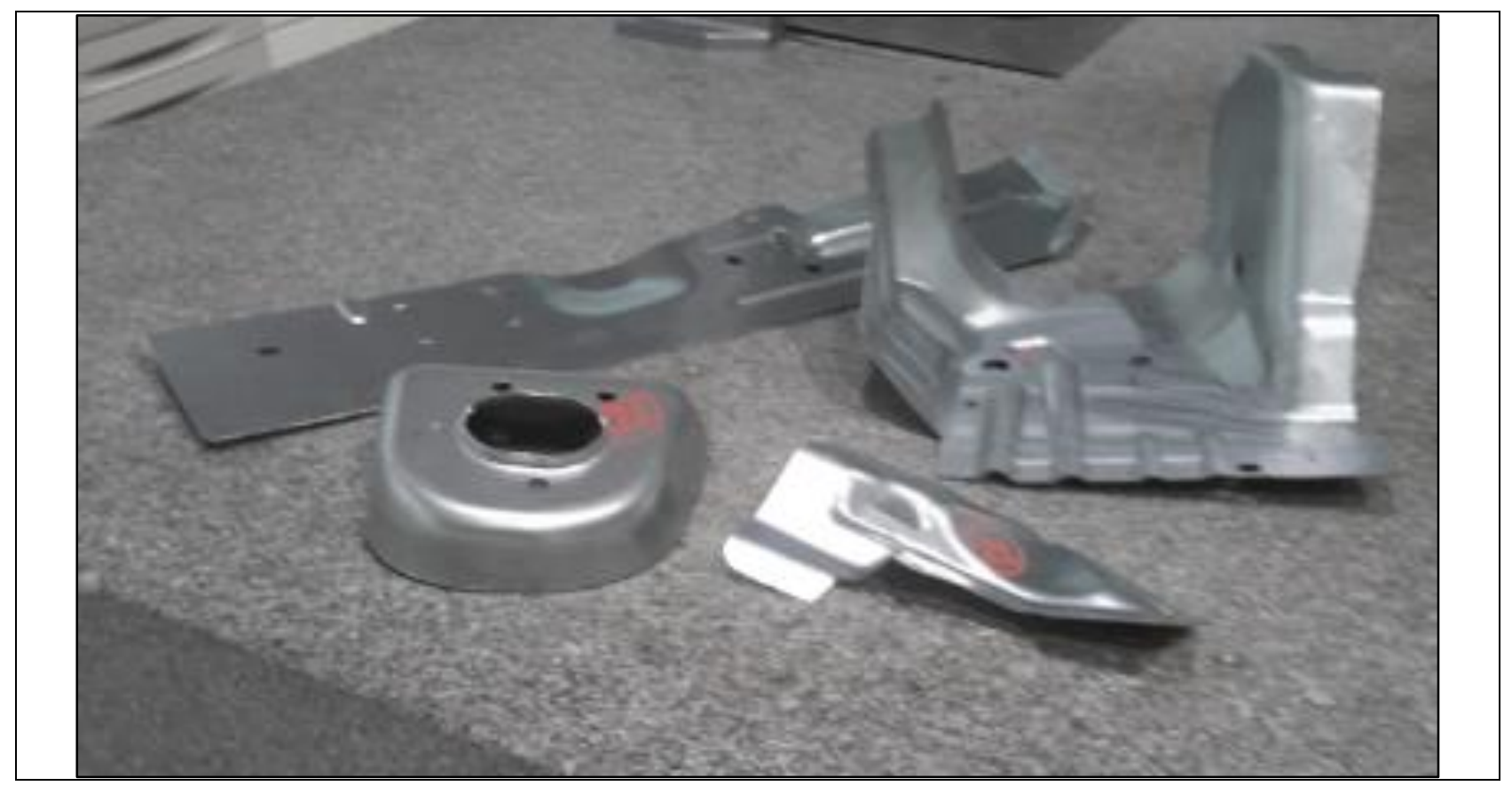

Fig. 4. Singular parts consisting the montage group

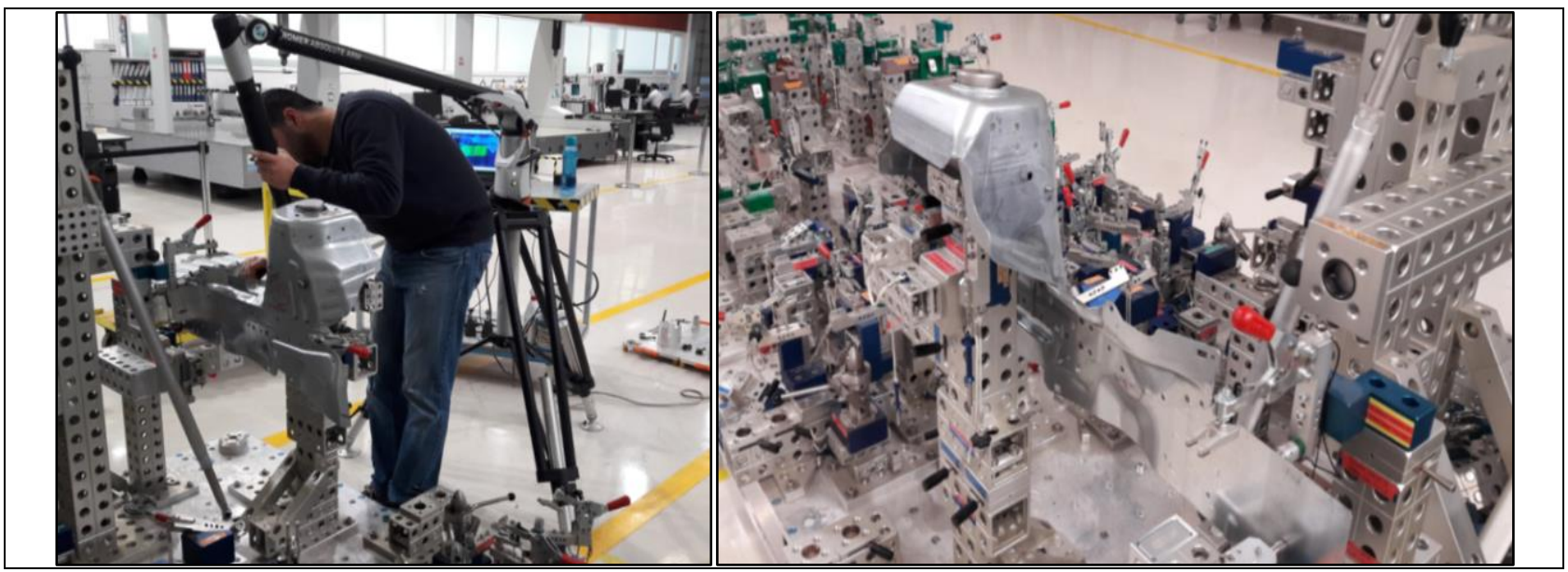

Fig. 5. A scanning and clamping example of the montage groups 


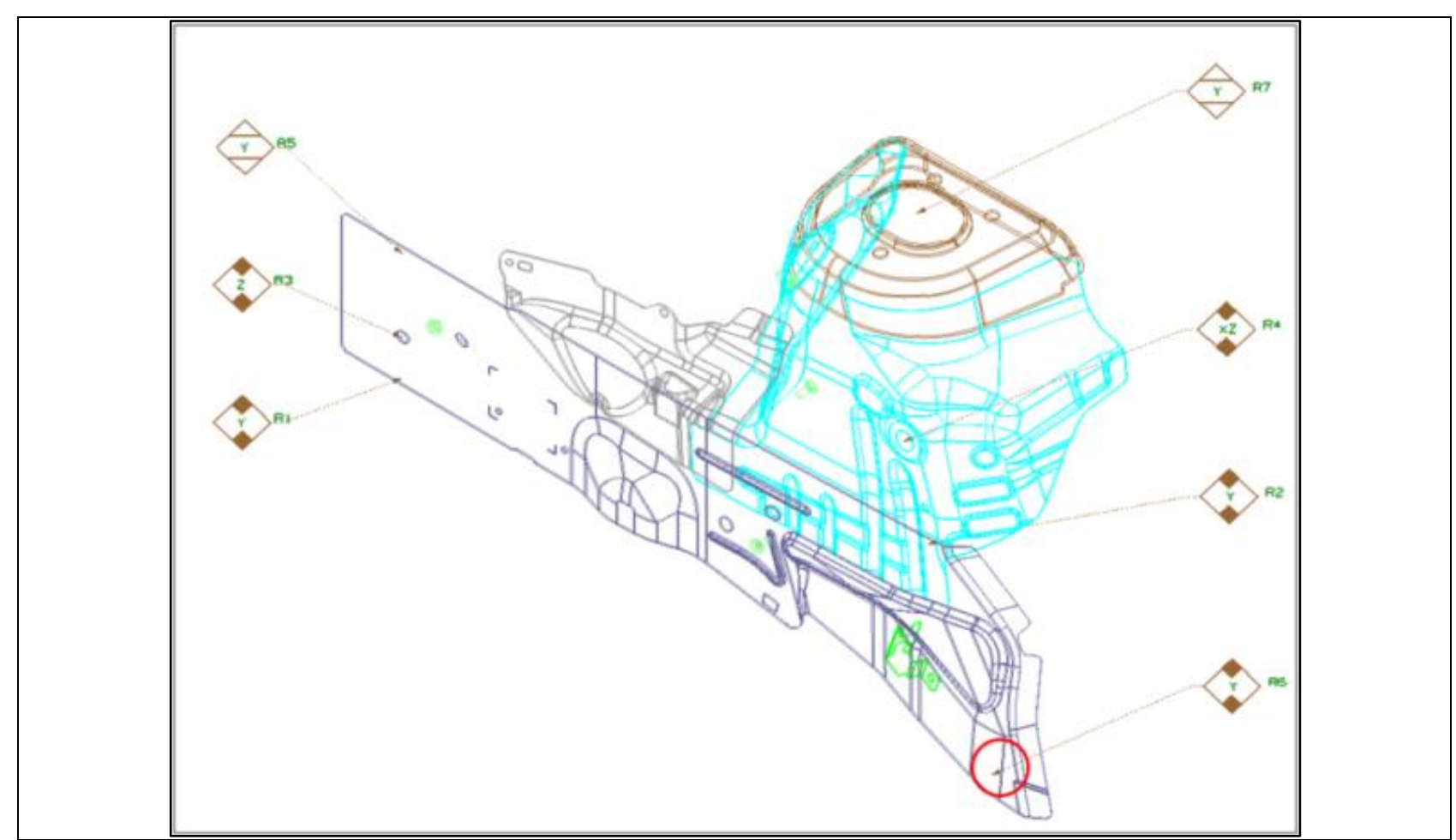

Fig. 6. The valid reference points for the assembled group

The scanning data of singular parts and montage groups have been aligned with CAD data in the software Polyworks and scanning reports have been prepared for every part according to the previously determined points. (Fig. 7)

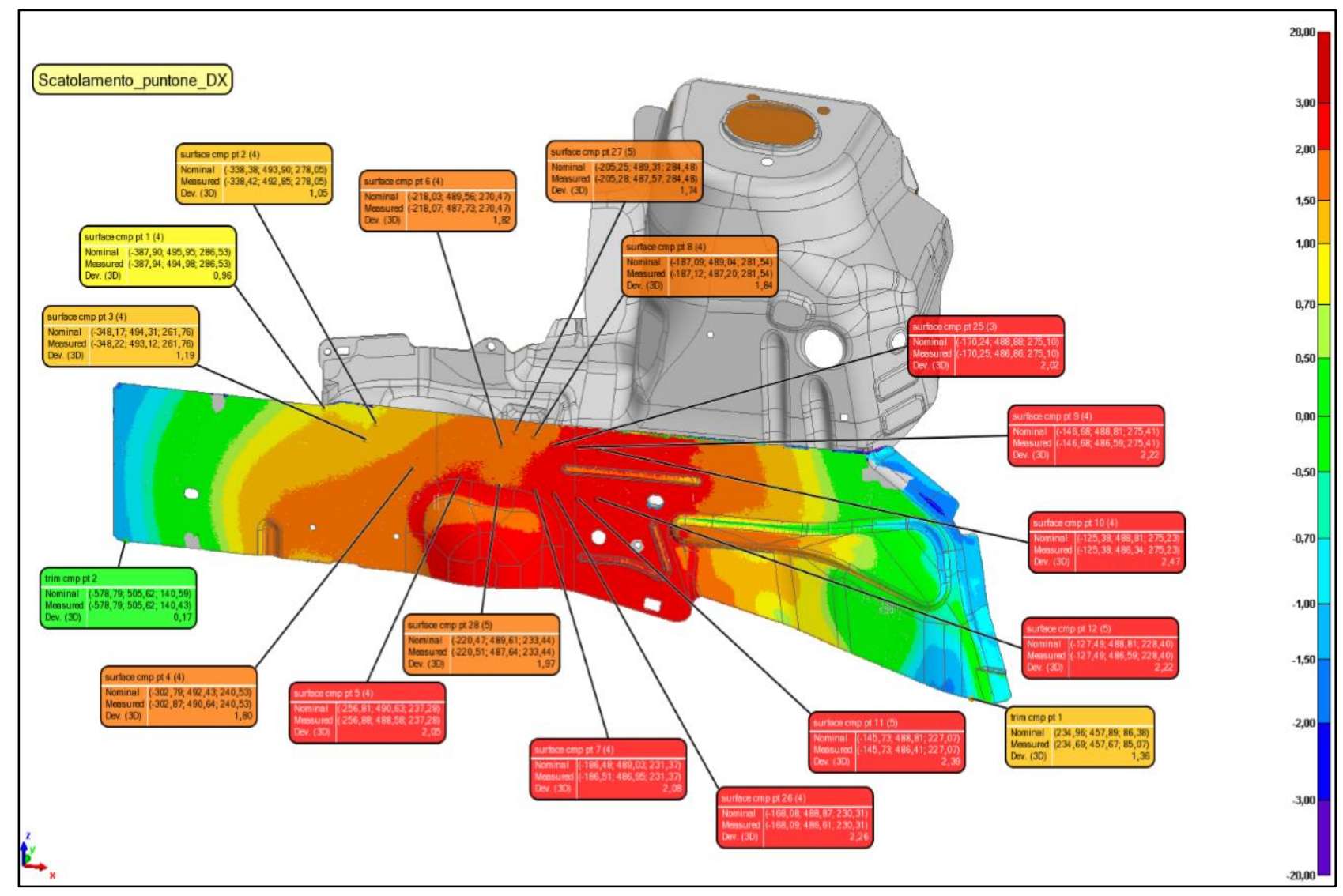

Fig. 7. A scanning report example 
Yurci, C.; Akdogan, A. \& Durakbasa, N.: A Case Study - Resistance Spot Weldin...

\subsection{Setting Analysing}

The whole welding procedure has been modelled in the software Weld Planner. Weld Planner is a welding analysis software of ESI Group which works according to the Local Shrinkage Principle. It considers thermal stresses by shrinkage after thermal expansion but it does not consider the welding parameters. It is mostly used to determine the welding sequence and the location of clamps. The welding sequence consists of two steps. After the first step the assembly group is unclamped and connected in the second stage to another clamping group. During that, some constraints (marked with red circle) have been eliminated (Fig. 8). The material for the parts has been given because of library constraints as another HSLA material, FEE 420. Because we research the welding sequence the material choice will not generate an importance.

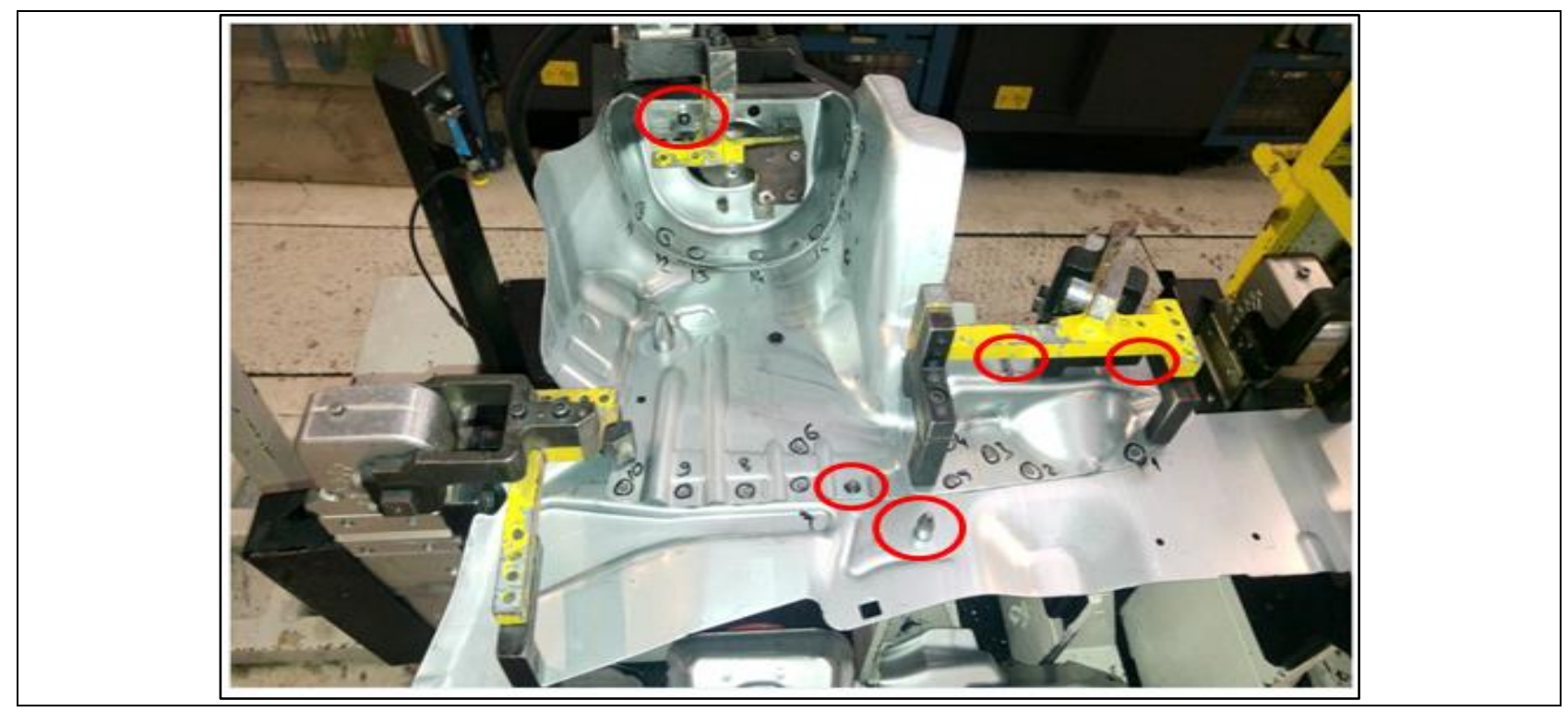

Fig. 8 . The pins marked with red circle have been eliminated in the second operation.

The gap and replacing the assembly group to the second clamping group has been modelled in Weld Planner with the specification 'Free Clamp' (Fig. 9 and 10).

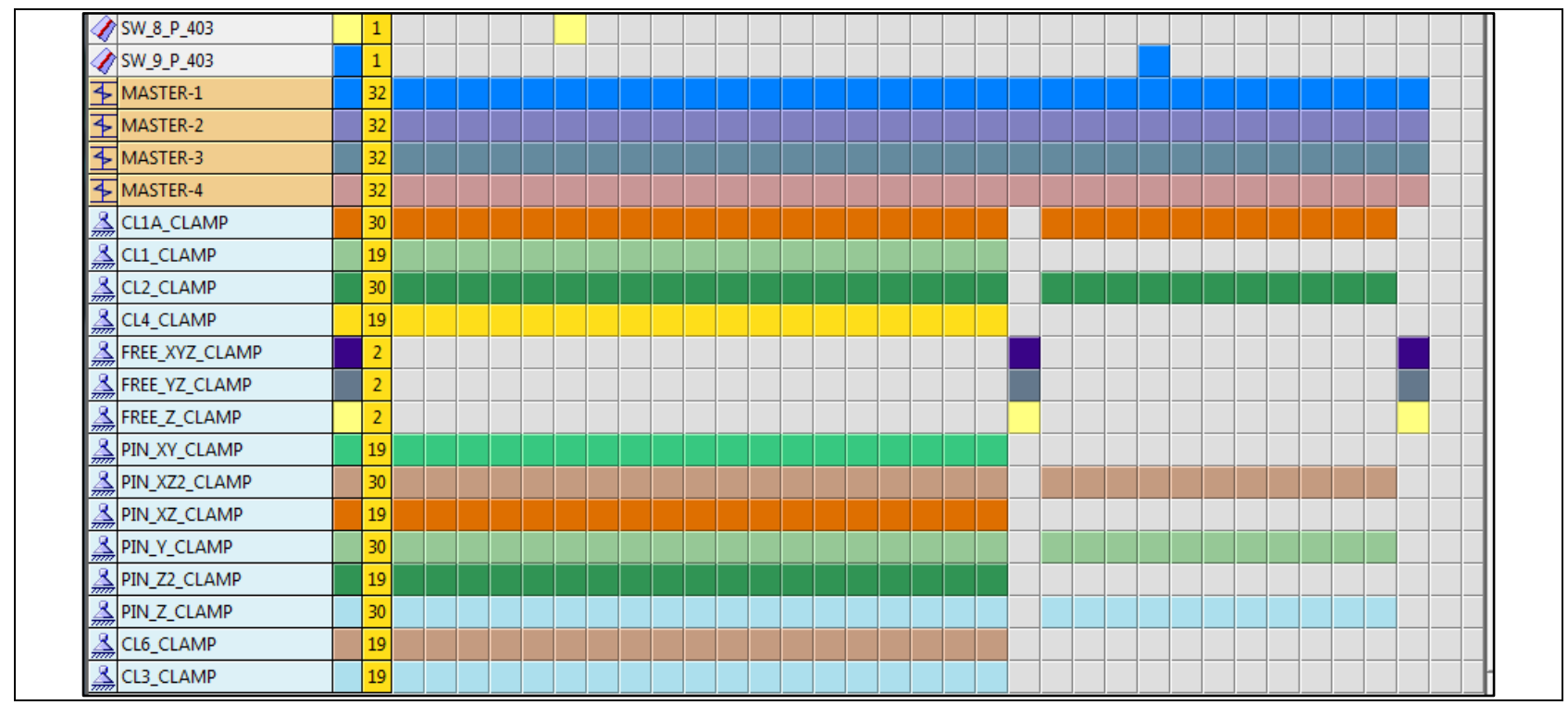

Fig. 9. The clampings given to Weld Planner 


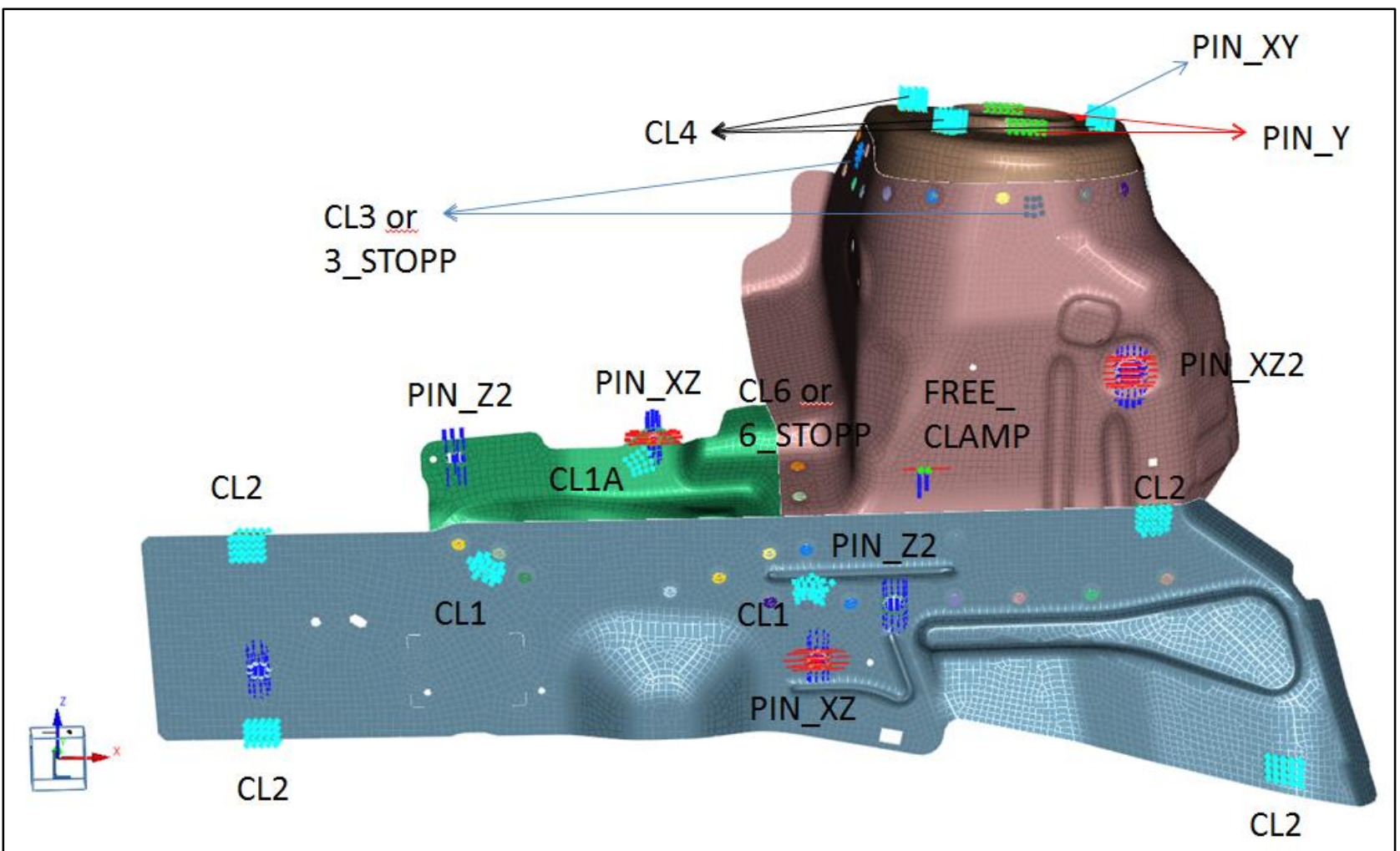

Fig. 10. The clampings on the assembly group according to Fig.9

\section{Results}

\subsection{Scanning Results}

As it is seen in Fig. 7, the scanning results have been obtained according to previously determined points. 5 groups for every sequence have been investigated. For the long part (Fig. 7) some distortion values for certain points are given (Table 1).

\begin{tabular}{|l|r|r|r|r|r|r|r|r|r|r|r|}
\hline Deviation Exp No 1 & Exp No 2 & Exp No 3 & Exp No 4 & Exp No 5 & Exp No 6 & Exp No 7 & Exp No 8 & Exp No 9 & Exp No 10 \\
\hline Cmp Pt 4 & $-0,81$ & $-1,16$ & $-0,71$ & $-1,07$ & $-0,66$ & $-1,53$ & $-1,38$ & $-1,27$ & $-1,2$ & $-1,34$ \\
\hline Cmp Pt 5 & $-1,56$ & $-2,03$ & $-1,61$ & $-1,63$ & $-1,41$ & $-2,24$ & $-2,01$ & $-1,89$ & $-1,83$ & $-1,99$ \\
\hline Cmp Pt 28 & $-1,78$ & $-2,32$ & $-1,81$ & $-1,82$ & $-1,62$ & $-2,46$ & $-2,14$ & $-2,09$ & $-1,96$ & $-2,16$ \\
\hline Cmp Pt 7 & $-1,97$ & $-2,56$ & $-1,97$ & $-1,88$ & $-1,81$ & $-2,67$ & $-2,25$ & $-2,26$ & $-2,17$ & $-2,34$ \\
\hline Cmp Pt 26 & $-1,93$ & $-2,58$ & -2 & $-1,96$ & $-1,85$ & $-2,73$ & $-2,29$ & $-2,27$ & $-2,2$ & $-2,37$ \\
\hline Cmp Pt 11 & $-2,08$ & $-2,67$ & $-2,07$ & $-2,01$ & $-1,87$ & $-2,85$ & $-2,32$ & $-2,36$ & $-2,28$ & $-2,45$ \\
\hline Cmp Pt 12 & $-2,07$ & $-2,54$ & $-2,01$ & $-1,95$ & $-1,84$ & $-2,9$ & $-2,29$ & $-2,4$ & $-2,26$ & $-2,46$ \\
\hline Cmp Pt 10 & $-2,61$ & $-3,3$ & $-2,67$ & $-2,69$ & $-2,51$ & $-3,43$ & $-2,78$ & $-2,92$ & $-2,82$ & $-2,99$ \\
\hline Cmp Pt 9 & $-2,31$ & $-2,95$ & $-2,33$ & $-2,33$ & $-2,22$ & $-3,11$ & $-2,43$ & $-2,56$ & $-2,44$ & $-2,63$ \\
\hline Cmp Pt 25 & $-2,01$ & $-2,67$ & $-2,09$ & $-2,12$ & $-1,97$ & $-2,79$ & $-2,19$ & $-2,28$ & $-2,16$ & $-2,36$ \\
\hline Cmp Pt 8 & $-2,01$ & $-2,61$ & $-2,03$ & $-2,12$ & $-2,01$ & $-2,74$ & $-2,21$ & $-2,28$ & $-2,13$ & $-2,34$ \\
\hline Cmp Pt 27 & $-2,02$ & $-2,57$ & $-2,07$ & $-2,04$ & $-1,96$ & $-2,66$ & $-2,16$ & $-2,23$ & $-2,07$ & $-2,28$ \\
\hline Cmp Pt 6 & $-1,89$ & $-2,43$ & $-1,91$ & $-1,92$ & $-1,8$ & $-2,51$ & $-2,1$ & $-2,12$ & $-1,97$ & $-2,18$ \\
\hline Cmp Pt 2 & $-0,43$ & $-0,81$ & $-0,32$ & $-0,24$ & $-0,32$ & $-0,7$ & $-0,59$ & $-0,55$ & $-0,49$ & $-0,58$ \\
\hline Cmp Pt 3 & $-0,35$ & $-0,69$ & $-0,19$ & $-0,3$ & $-0,22$ & $-0,67$ & $-0,61$ & $-0,5$ & $-0,49$ \\
\hline Cmp Pt 1 & $-0,14$ & $-0,53$ & $-0,02$ & $-0,18$ & $-0,02$ & $-0,3$ & $-0,28$ & $-0,3$ & $-0,23$ \\
\hline
\end{tabular}

Tab. 1. Distortion results at pre-determined points for two welding sequences 
The first 5 distortion values for results for every point indicate the distortion values for Sequence 1 and the last five values indicate the deviation values for Sequence 2. According to the distortion values for Point 4 and the Sequence 1 the process and performance capability results are as follow (Fig. 11). These values have been calculated according to the standard (DIN ISO 22514-2).

From the analysis of the normal distribution, we know that USL and LSL lines determine the area covering $99.7 \%$ of the population (below the curve of the normal distribution). Because of the symmetry of the normal distribution, part of the population outside the USL and LSL lines are identical. For the method of the normal distribution, the capability indicator estimators are equivalent to the indicators being traditionally defined according to the standard (ISO/TR 22514-4). Considering the $\mathrm{C}_{\mathrm{p}}$ and $\mathrm{C}_{\mathrm{pk}}$ values the process is capable (Fig. 11).

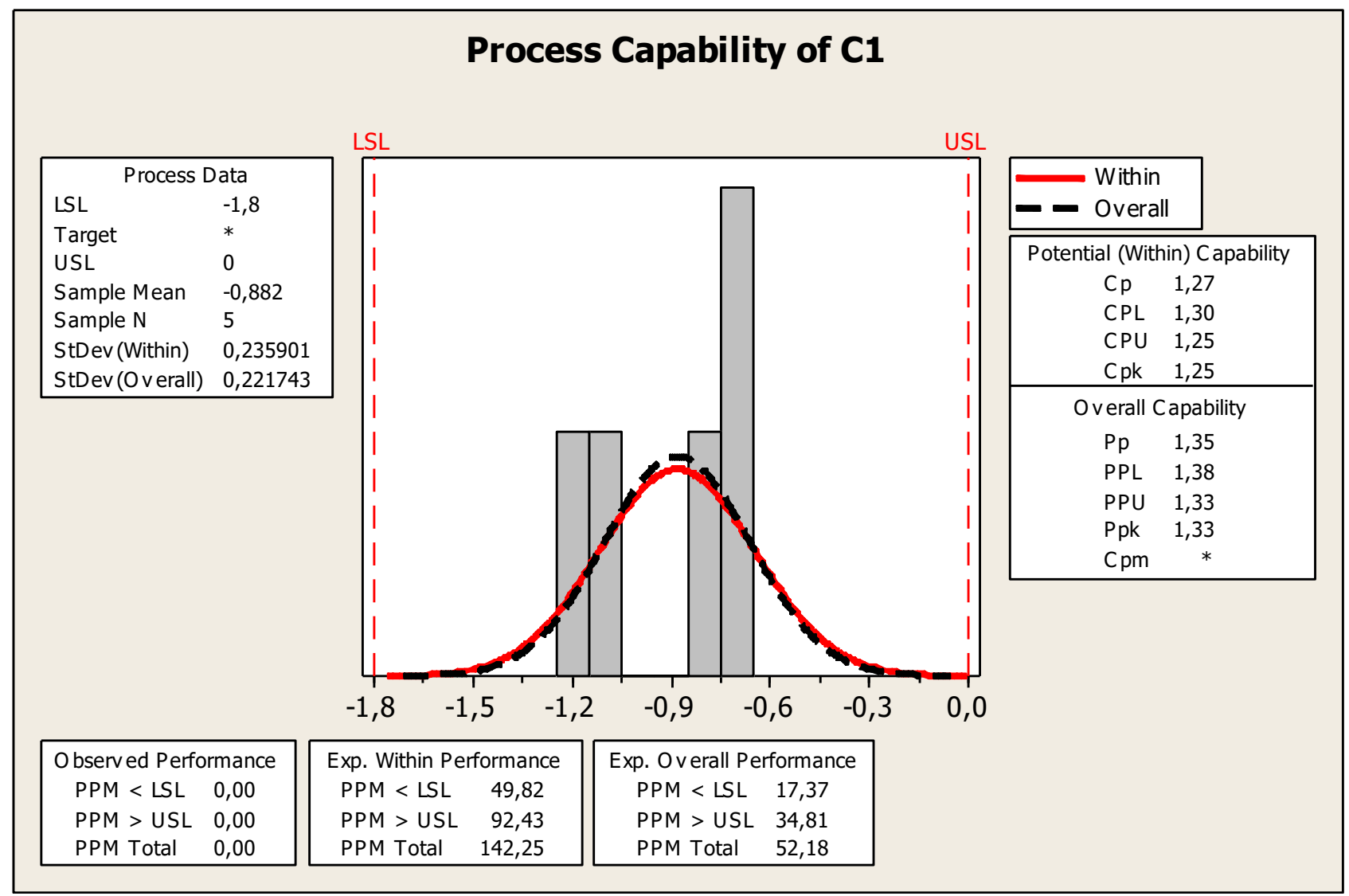

Fig. 11. Process capability statistics

\subsection{Analysing Results}

Several analyses have been made in Weld Planner according to the montage group. During that, clamp or stopp assignments have been made or welding sequence of spots have been changed.

During the stopp (the name in the software) assignment the region is constrained by one direction. The welding sequences in Fig. 3 have been applied. The deviation results over the part data are given in Fig. 12. 


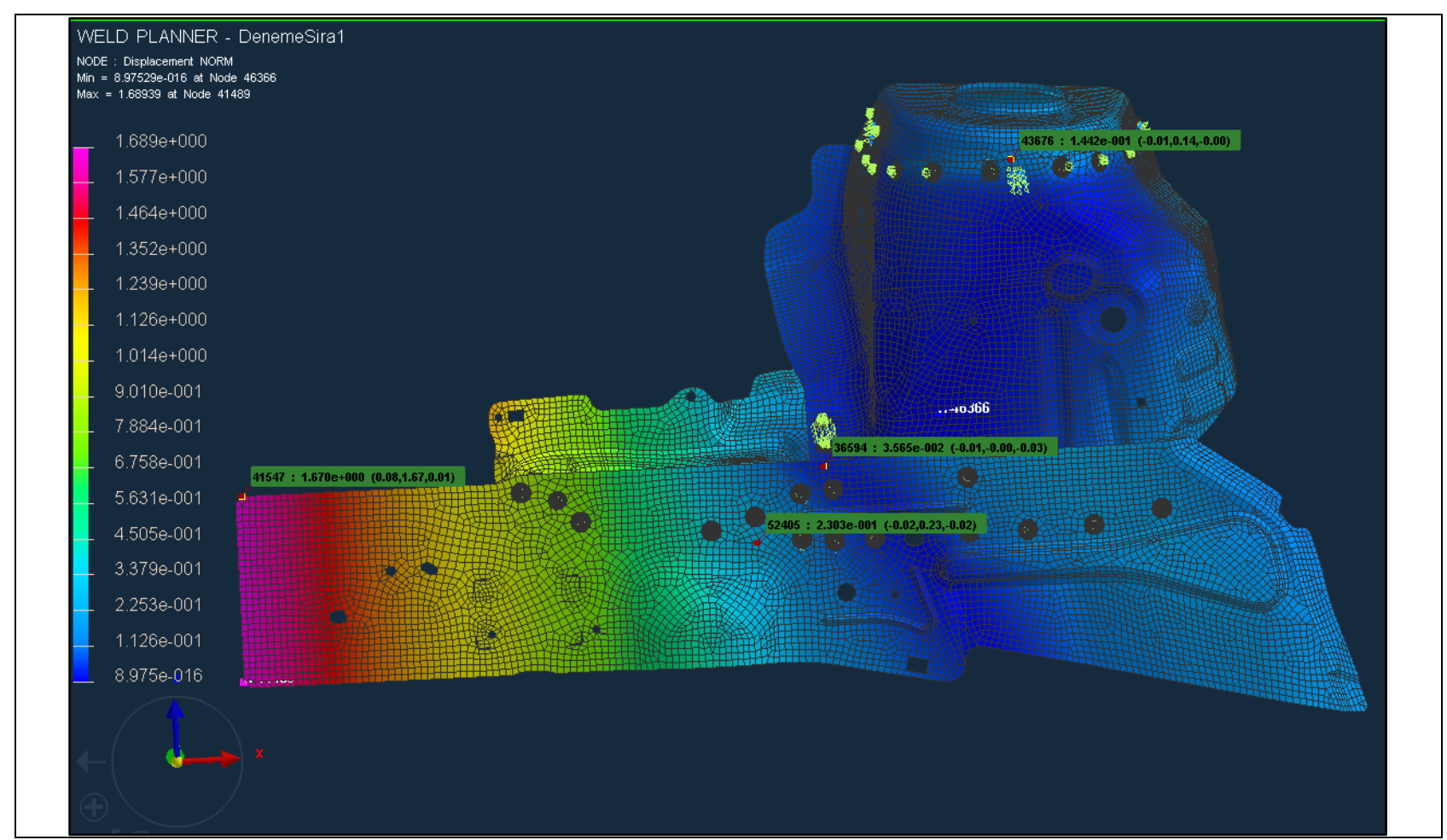

\section{Sequence 1}

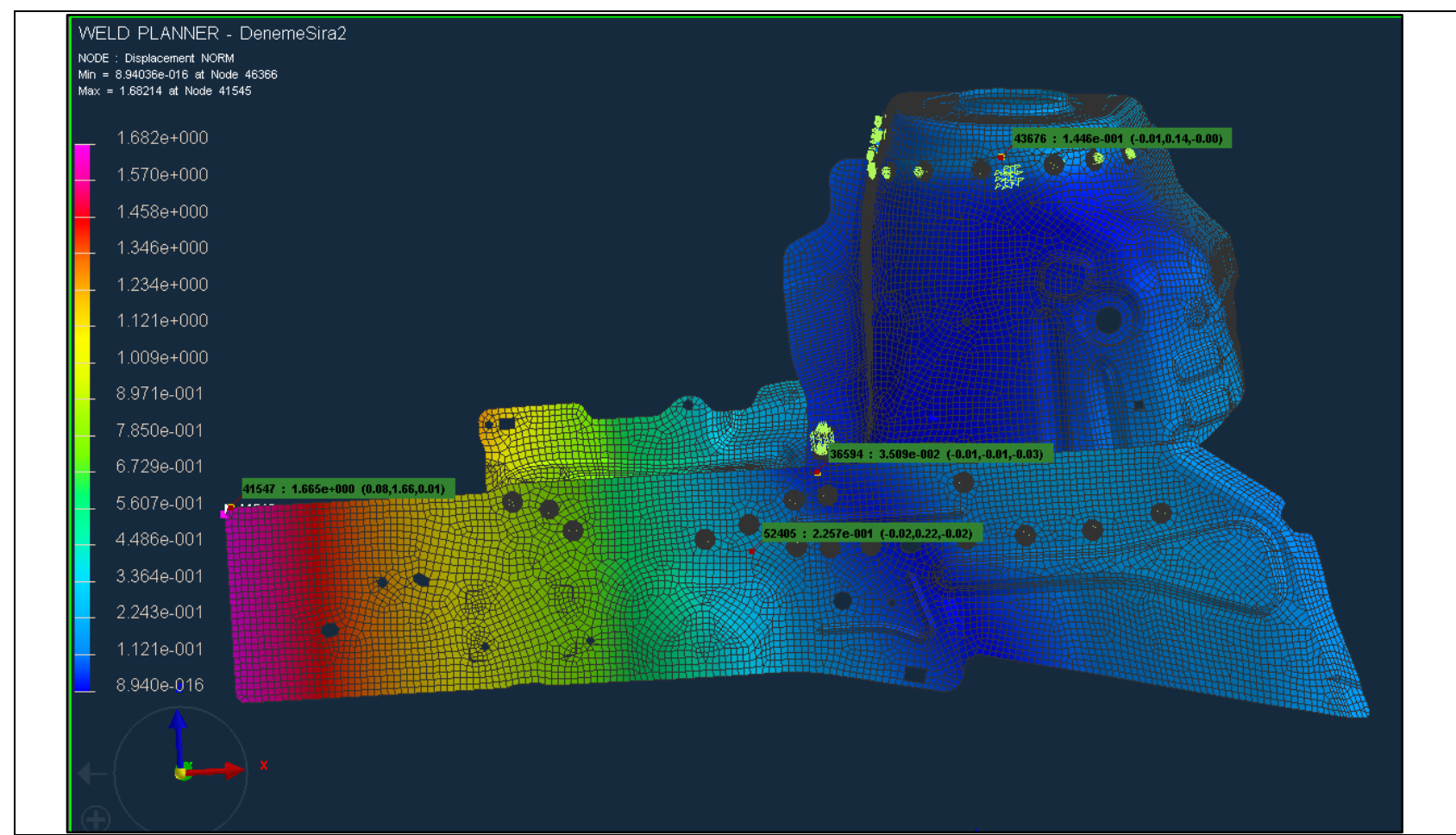

Sequence 2

Fig. 12. Analysing results for two sequences

The deviations marked in the upper figure can be given from left to the right so:

Sequence 1:

$\begin{array}{llll}1.670 & 0.2303 & 0.03565 & 0.1442\end{array}$

Sequence 2:

$\begin{array}{llll}1.665 & 0.2257 & 0.03509 & 0.01446\end{array}$ 
Yurci, C.; Akdogan, A. \& Durakbasa, N.: A Case Study - Resistance Spot Weldin...

If the stopp on the curved upper part is changed to the clamping; the distortions are as follow:

\section{Sequence 1:}
1.672
0.035
0.155

Sequence 2:
1.647
$0.036 \quad 0.150$

Two other sequences have been tried, too.
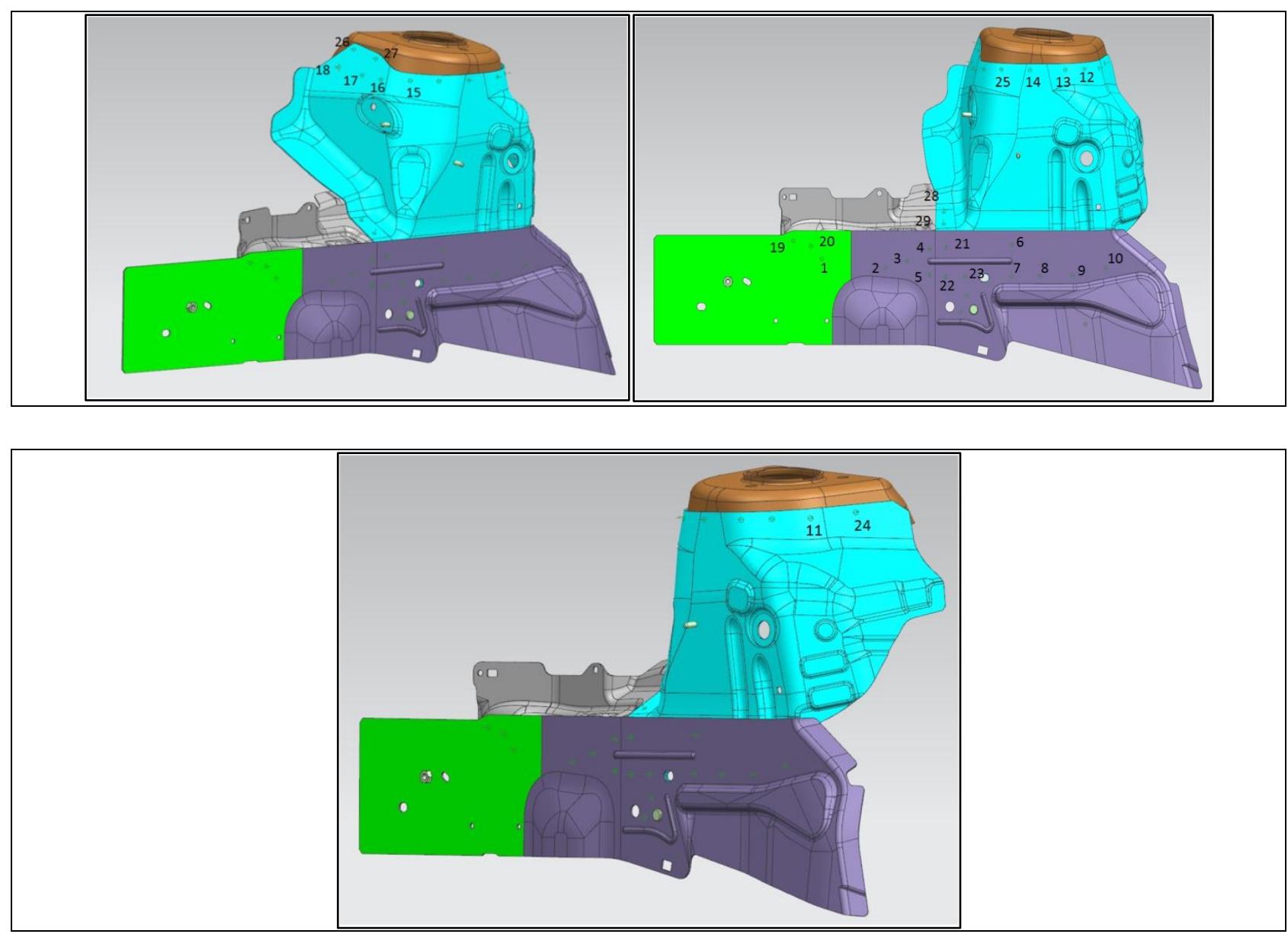

Sequence 3

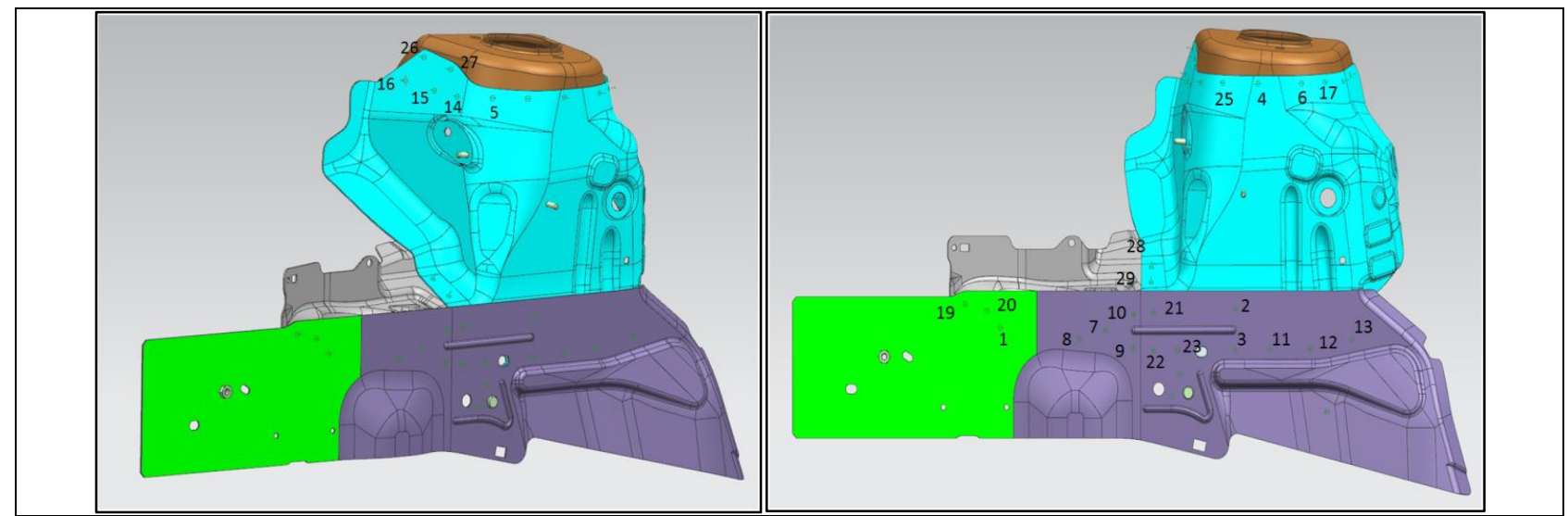




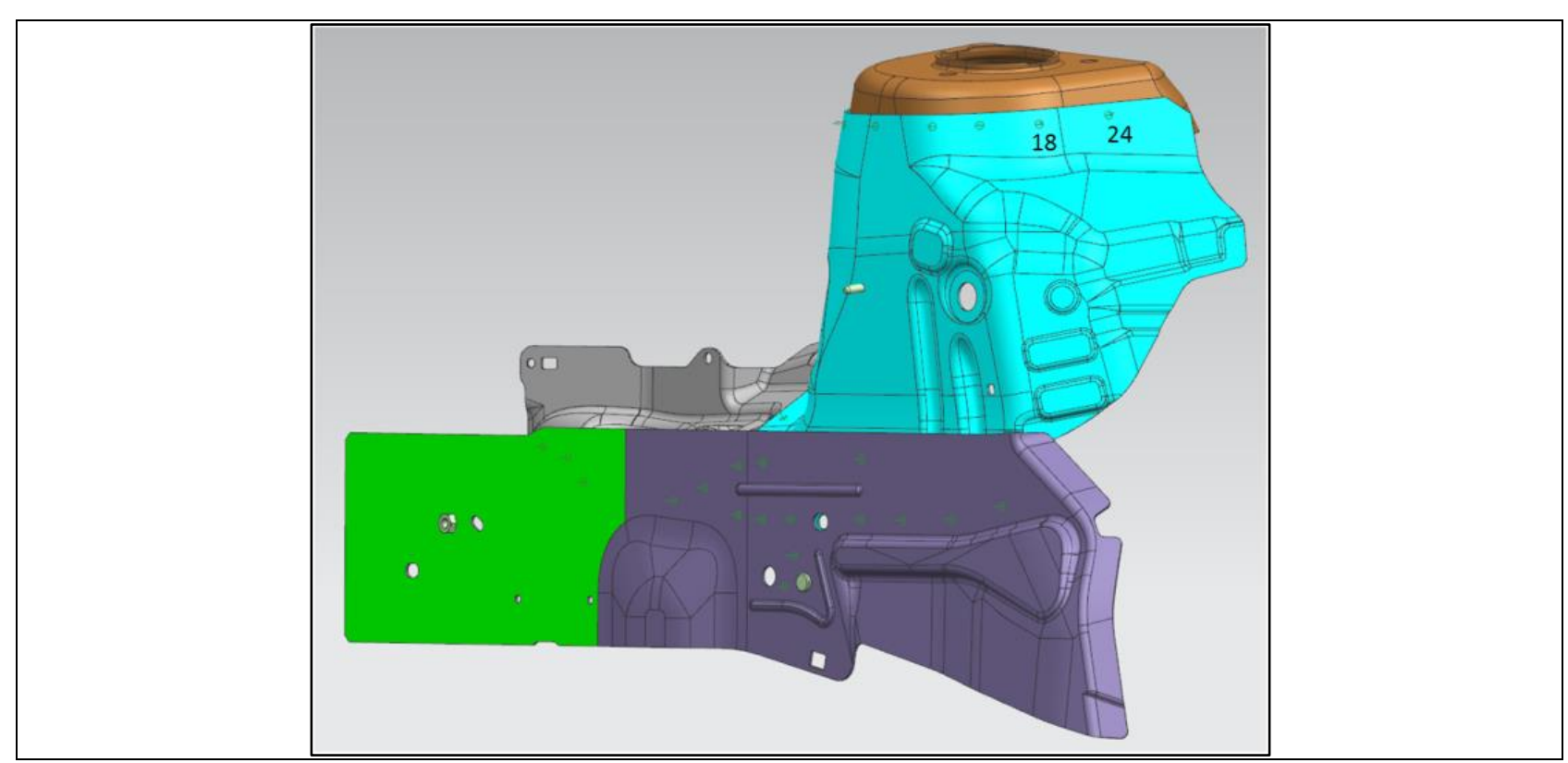

\section{Sequence 4}

Fig. 13. Applied two other welding sequences for the assembly group

The distortion results for these sequences and with clamping are as follow:

Sequence 3:
1.674
0.035
0.155

Sequence 4:
1.646
$0.03558 \quad 0.1508$

Generally, the second sequences begin from the upper curved part.

\section{Conclusions}

Two different welding sequences have been applied in real application on the manufacturing line. It has been observed that the distortions are increased with the second welding sequence. By that the spot welding began by the first points on the upper curved part. Although it is hard to find a certain and exact explanation why the distortions are increased by this spot welding sequence some explanations can be made. By the second sequence the spot points are assigned unordered. They are employed like tack welding. Because of that it can be that these tack welding points act like clamping points. If clamping points were applied, after releasing of clampings the main distortions would exist. Here an extra residual stress might have been loaded to the system which can cause more deformation. Another reason can be the above explained shunt effect. By the first sequence more current flow might have flowed from shunted to other shunt welds.

By analysing several results are being observed. According to the Fig. 12, by the sequence 2, distortions are decreased. But the distortion on the curved part is increased. However it must be considered that the distortions by changing the sequence or clamping-stopp properties the distortions are almost the same. Also there are very little 
differences between the magnitudes by these analyses. The results of the 1st and 3rd sequence and 2 nd and 4th sequence are almost the same because their orders are so similar.

By changing the sequence according to the Fig. 13, again the distortions did not change. But at this time the distortion on the centre of the long part increases. The others decrease.

The differences between the analysis results according to several welding sequences are very small. But here is important to see the changing trend if it increases or decreases. This can give an opinion about the effects of welding sequences. A direct relationship between scanning and analysing can not be built. Although at some points the scanning and analysing results match, at some points they do not match. This has another reason. At this montage group especially the middle region of the long part (red region- Fig. 7) is exposed to the electrode force. But in Weld Planner the electrode forces can not be modelled. Because of that a deformation in $-Y$ direction occurs which can not be seen in Weld Planner. So, because of that and because the parts are of course integrated, the whole deformation of the assembly group is dependent and they affect on each other in all regions of the group.

This process has a complex structure depending on factors such as welding parameters, welding points locations, sizes, part geometry, part size and shunt effect. So a certain explanation about the effect of welding sequence on the distortions can not be made. The mentioned factors and the here researched welding sequence effect have an impact on the process in an integrated manner while they are affecting on each other, too. In our other studies for the detailed investigation of the mentioned montage group and of other parts an exact effect explanation can not be made for welding parameters, too. They are in interaction with other effects.

So, this study and its conclusions have been added to the very rare studies investigating the welding sequence for resistance spot welding distortions. This work has been made to generate the aim of minimizing total deviation from the absolute form and dimensions. For example, with assigning the correct welding sequence the deviations before welding (for instance springbacks after bending) can be compensated. In future, the studies can be broadened to the investigation of other process parameters with the welding sequence in an integrated manner.

\section{Acknowledgement}

This work was supported by Research Fund of the Y1ldız Technical University. Project Number: 2014-06-01-DOP04. We thank the Research Fund of Y1ld1z Technical University for their support. 


\section{References}

Bi, J.; Song, J.; Wei, Q.; Zhang, Y.; Li, Y. \& Luo, Z. (2016). Characteristics of shunting in resistance spot welding for dissimilar unequal-thickness aluminum alloys under large thickness ratio. Materials and Design, Vol. 101, 2016, pp. 226-235

Bielenin, M.; Konstantin, S.; Bergmann, J. P.\& Neudel, C. (2016). EinseitigesWiderstandsfügeverfahren für metallische Mischverbindungen sowie Hybridverbindungan aus thermoplastischen Kunststoffen und Metallen. DVS Berichte, 23. DVS_Sondertagung, Duisburg, 978-3-945023-75-4, pp. 7-15, DVS Media GmbH, Düsseldorf

Catana, D. (2010). Traction behaviour simulation of spot welded. DAAAM International Scientific Book. DAAAM International, 978-3-901509-74-2, Vienna, Chapter 50, pp. 575-582

Chen, Z.; Chen, Z. \& Shenoi, R. A. (2015). Influence of welding sequence on welding deformation and residual stress of a stiffened plate structure. Ocean Engineering, Vol. 106, 2015, pp. 271-280

Dahlström, S.; Lindkvist, L. \& Söderberg, R. (2007). Practical implications in tolerance analysis of sheet metal assemblies: experiences from an automotive application. Models for Computer Aided Tolerancing in Design and Manufacturing, 2007, pp. 311 320

DIN EN ISO 14373 Resistance welding - Procedure for spot welding of uncoated and coated low carbon steels (ISO 14373:2015)

DIN ISO 22514-2 Statistical methods in process management - Capability and performance - Part 2: Process capability and performance of time-dependent process models (ISO 22514-2:2013)

Doyen, O.; Rizzo, N.; Forest, L; Tosi, J.; Thomas, N.\& Zmitko, M. (2017). Assessment of HCLL-TBM optimum welding sequence scenario to minimize welding distortions. Fusion Engineering Design, Vol. 121, 2017, pp. 80-86

Folchi, F. (2014). Weld distortion prediction with virtual analysis for practical applications. M. Sc. Degree, Department of Mechanical, Automotive and Material Engineering, University of Windsor, Ontario, Canada

Francis, J. D. (2002). Welding Simulation of aluminum alloy joints be finite element analysis. M. Sc. Degree, Faculty of the Virginia Polytechnic Institute, Virgina State University, Virginia, USA

Fu, G.; Lourenço, M. L.; Duan, M. \& Estefen, S. F. (2016). Influence of the welding sequence on residual stress and distortion of fillet welded structures. Marine Structures, Vol. 46, 2016, pp.30-55

ISO/TR 22514-4:2007 Statistical methods in process management - Capability and performance - Part 4: Process capability estimates and performance measures

Jackson, K. \& Darlington, R. Advanced Engineering Methods of Assessing Welding Distortion in Aero- Engine Assemblies. Trends in Aerospace Manufacturing 2009 
Yurci, C.; Akdogan, A. \& Durakbasa, N.: A Case Study - Resistance Spot Weldin...

International Conference, IOP Conf. Series: Materials Science and Engineering, Vol. 26, 2011, pp. 1-20

Moos, S. \& Vezzetti, E. (2015). Resistance spot welding process simulation for variational analysis on compliant assemblies. Journal of Manufacturing System, Vol. 12, 2015, pp. 44-71

Mrvar, P.; Medved, J. \& Kastelic, S. (2011). Welding sequence definition using numerical calculation. Welding Journal, Vol. 90, 2011, pp.148-151

Neumann, H.; Moravec, J. \& Bradac, J. (2010). The welding process effect on the iron aluminide Fe3Al, Metal 2010, Ceska Republica

Schreiber, S.; Zak, P. \& Wilhelm, T. (2016). Unsere Welt ohne Widerstandsschweissen - da würde uns etwas fehlen. DVS-Berichte, 23. DVS_Sondertagung, Duisburg, 9783-945023-75-4, pp. 1-6, DVS Media GmbH, Düsseldorf

Shanmugam, N. S.; Buvanashekaran, G.; Sankaranarayanasamy, K. \& Kumar, S. R. (2010). A transient finite element simulation of the temperature and bead profiles of Tjoint laser welds. Materials and Design, Vol. 31, No. 9, 2010, pp. 4528-4542

Shaoyun, C.; Zhongqin ,L.; Yizhu, Z. \& Yongbing, L. (2006). A parametric study of sheet metal joints for dimensional integrity. Int J Adv Manuf Technol, Vol. 29, 2006, pp. 446-452

Sulaiman, M. S.; Manurung, Y. H.; Haruman, E.; Rahim, M. R. A.; Redza, M. R.;Lidam, R. N. A.; Abas, S. K.; Tham, G. \& Chau, C. Y. (2011). Simulation and experimental study on distortion of butt and T-joints using Weld Planner. Journal of Mechanical Science and Technology, Vol. 25, No. 10, 2011, pp. 2641-2646

Zhang, H. \& Senkara, J. (2012). Resistance Welding Fundamentals and Applications, CRC Press Taylor \& Francis Group, 978-1-4398-5371-9, Boca Raton 